\title{
Application of the AE Technique to Fracture Processes in Glassy Polymers III.
}

\author{
Tetsuya NishiURA, Takashi JOH, Shogo OKUDA,* \\ and Masanobu MIKI* \\ The Institute of Scientific and Industrial Research, \\ Osaka University, Mihogaoka, Ibaragi, Osaka 567, Japan \\ *Faculty of Domestic Science, Teikoku Women's University, \\ Tohdacho, Moriguchi, Osaka 575, Japan
}

(Received June 7, 1983)

KEY WORDS Acoustic Emission / Craze / Fracture / Glassy Polymer /

Correlation between acoustic emission (AE) and fracture processes in glassy polymers has been investigated actively at our laboratory to clarify the fracture mechanism of glassy polymers. Our previous papers ${ }^{1-3}$ showed that $\mathrm{AE}$ emerged from PMMA specimens immersed in various alcohols when subjected to tensile stress and that the $\mathrm{AE}$ behavior appeared to be correlated with craze growth and also the formation of the characteristic fracture surface (shell-like patterns).

In this work, an attempt was made to clarify such correlation in more detail. For this purpose, a relaxation test was performed, since it allows craze and crack processes to observe more clearly and easily than in tensile tests. ${ }^{1-3}$ In this test, craze and crack propagate slowly, with only a few crazes created.

A single edge notched specimen* $(30 \times 150 \times$ $1 \mathrm{~mm}$, notch root radius $0.1 \mathrm{~mm}$ ) made from a sheet of PMMA $\left(T_{\mathrm{g}} 90^{\circ} \mathrm{C}\right.$, Comoglass, Kyowa Gas Chemical Co., Ltd.) was immersed in isopropanol, a typical agent used in our previous investigations, ${ }^{2,3}$ and then set on an Instron Tensile machine. A definite tensile load was applied to the specimen, the elongation due to the applied load was kept constant, and the stress relaxation test was allowed to proceed. Detection of $\mathrm{AE}$ signals and observation of crazes and cracks were simultaneously performed by the same procedure as that described in the previous papers. ${ }^{1,3}$ All experiments were conducted at $18^{\circ} \mathrm{C}$.

Figure 1 shows the relaxation load, the craze length, and summation of $\mathrm{AE}$ counts as function of time. In a lower load relaxation test, characterized by a slow initial decrease in load, both craze length and $\mathrm{AE}$ counts increased slowly, and after a certain period, a sharp decrease in load occurred accom-
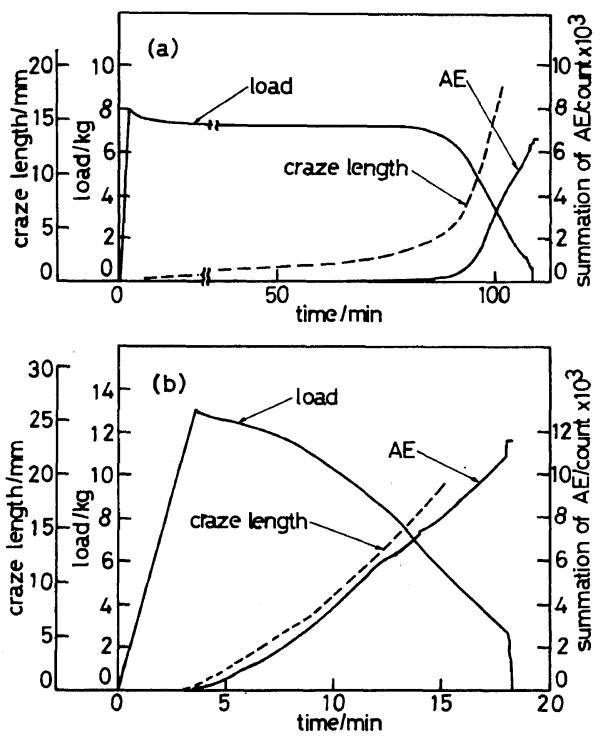

Figure 1. Relation of relaxation load, summation of AE counts, and craze growth length. (a), lower initial load, $8 \mathrm{~kg}$; (b), higher initial load, $13 \mathrm{~kg}$.

* The specimen was annealed at $80^{\circ} \mathrm{C}$ for $1 \mathrm{~h}$ before the test. 
panying a drastic increase in craze length and $\mathrm{AE}$ count. In a higher load relaxation test, the load decreased rapidly with rapid increase in craze length and AE counts. These findings clearly suggest that load relaxation, craze length, and AE counts were correlated with each other.

The behavior of craze growth was examined in detail. When the specimens were strained, craze was created at the notch root, developed slowly to a certain length, and then extended abruptly and linearly to a certain length. The craze again extended slowly, often accompanied with a disturbed extension like a tree branch (Figure 2). Thus, craze seems to extend, repeating these slow and fast stages alternately. AE was detected just at the abrupt and linear craze extension, but not at the initiation and during the slow extension. In the previous tensile tests, ${ }^{1-3}$ such an abrupt and linear craze extension was not observed, and it appeared that AE resulted from an abrupt and tree branch like craze extension. This may be attributed to the fact that the load increased so fast and craze extended so fast that the linear abrupt craze extension could not be distinguished from the tree branch like extension.
Figure 3 shows the fracture surfaces observed under an optical microscope $(\times 50)$. It can be seen that the fracture surfaces are covered almost completely with characteristic shell patterns consisting of alternate bright and dark band regions. The dark band region is designated as the shell mark. The distance from the notch root to the first shell mark in a higher load relaxation test was shorter than that in a lower load test. At the first AE detected, the craze length was shorter for the higher initial load than for the lower initial load (Figure 1). The craze length at the first AE detection was thus considered to relate to the distance from the notch root to the first shell mark. Since any shell pattern could be well focused with an optical microscope, it appeared certain that the shell mark (dark region) and the bright region had the same height and were on the same plane.

These results indicate that the shell patterns were formed on the same craze plane or on a few craze planes.

To clarify the correlation between $\mathrm{AE}$ and crazing processes, the craze just after the detection of $\mathrm{AE}$ was observed by an optical microscope in-

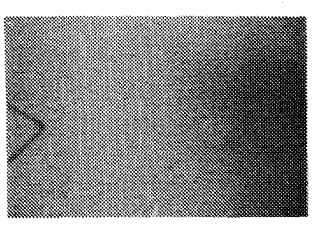

0

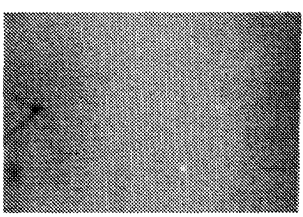

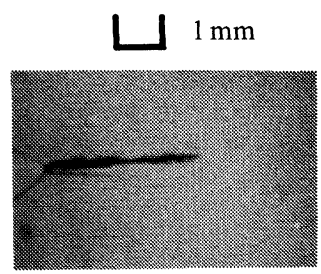

$6 \mathrm{~min}$

Figure 2. Craze growth behavior. Initial load, $13 \mathrm{~kg}$.

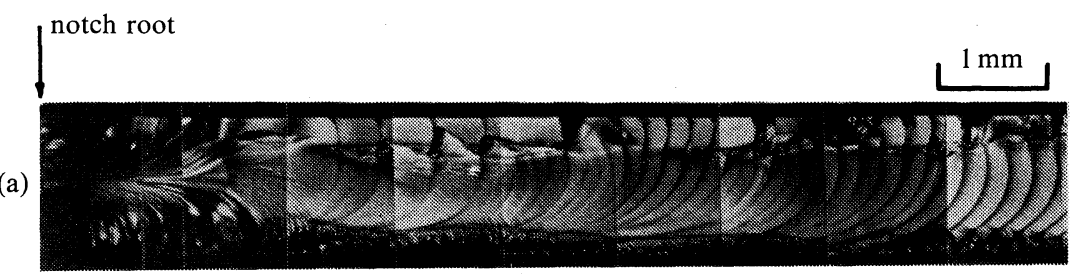

(b)

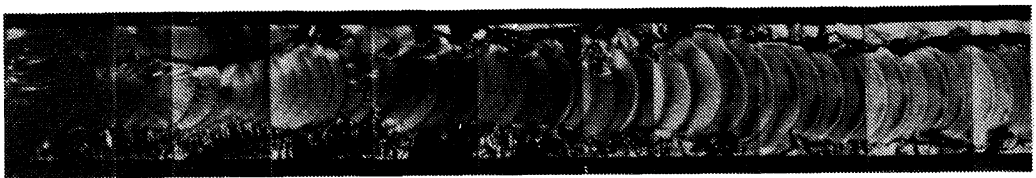

Figure 3. Fracture surfaces covered almost completely with characteristic shell patterns. (a) lower initial load, $8 \mathrm{~kg}$; (b) higher initial load, $13 \mathrm{~kg}$. 
Acoustic Emission of Glassy Polymers

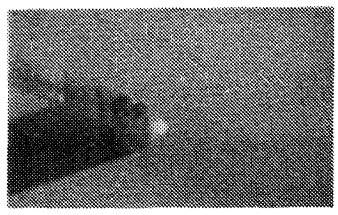

(a) non-AE

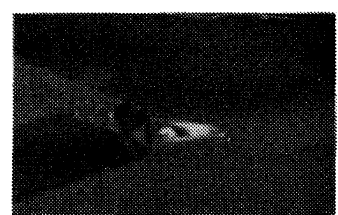

(b) 1 st $\mathrm{AE}$

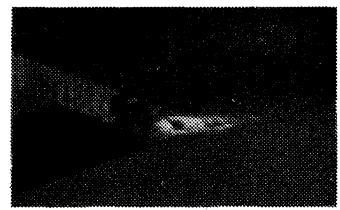

(d) 3rd AE

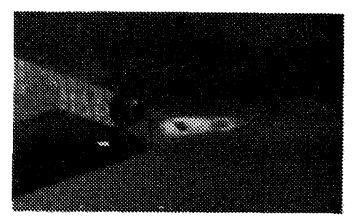

(c) 2nd AE

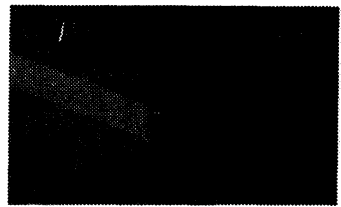

(e) after annealing

Figure 4. Observation with an optical microscope of a craze inclined to the specimen axis after loading off. (a) before AE detection; (b) after 1st AE detection; (c) after 2nd AE detection (d) after 3rd AE detection; (e) after annealing at $80^{\circ} \mathrm{C}$ for $1 \mathrm{~h}$.

clined to the load-off specimen axis. The results are shown in Figure 4. Before the AE detection, no shell marks were observed. But, after the first $\mathrm{AE}$ detection, a shell mark was observed, and after the second and third AE detections, two and three shell marks were observed. This correspondence of $\mathrm{AE}$ to shell marks indicates that AE signals emerge in the formation of shell marks in crazes. When the specimen after the third AE detection was kept at $80^{\circ} \mathrm{C}$ for one hour, the craze and shell marks disappeared almost completely. This recovery of shell patterns leads to the conclusion that the patterns consisted of crazes and were possibly formed during discontinuous growth of the crazes.

From the above findings, the following conclusions may be drawn. 1 . At least in the early stage of a relaxation test, $\mathrm{AE}$ signals emerge in the formation process of the shell marks. 2. Shell marks are formed in the crazing process. 3. The AE method can identify the character of the crazes.

In the final stage of this relaxation test, cracking occurred. Hence, AE in this stage may be a mixture of AE due to crazing and cracking. We plan to carry out an experiment by which crazing and cracking processes can be distinguished from each other.

\section{REFERENCES}

1. T. Nishiura, T. Joh, S. Okuda, and M. Miki, Polym. J., 13, 89 (1981).

2. T. Nishiura, T. Joh, S. Okuda, and M. Miki, Polym. J., 13, 611 (1981).

3. T. Nishiura, T. Joh, S. Okuda, and M. Miki, Zairyo, 32, 88 (1983). 